\title{
REGIME DE PROGRESSÃO CONTINUADA E AVALIAÇÃO EM UMA ESCOLA ESTADUAL NO MUNICÍPIO DE HUMAITÁ/AM
}

\author{
Daiana dos Santos Reis ${ }^{1}$ \\ Aldair Oliveira de Andrade ${ }^{2}$
}

\begin{abstract}
RESUMO
A Lei de Diretrizes e Bases da Educação no 9.394/96 prevê no artigo 32 §2, que as instituições escolares utilizem o Regime de Progressão Continuada (RPC), o qual está diretamente ligado à avaliação. A pesquisa objetiva demonstrar estatística e descritivamente a realidade da avaliação no Regime, destacando questões como tempo de aprendizagem, práticas avaliativas e acompanhamento individual a partir da perspectiva dos alunos com a qual foi realizada uma pesquisa no $9^{\circ}$ ano do Ensino Fundamental II, em uma Escola Estadual do Município de Humaitá/AM. Estudos sobre a temática possibilitaram identificar direitos previstos em lei que serviram de base para a nossa análise, enfatizando que todas as formas avaliativas são utilizadas em sala de aula, porém ainda há resquícios do ensino tradicional nas medidas utilizadas, com alunos que tendem a esperar por instruções e que o termo "reprovação" ainda se faz presente no contexto escolar, mesmo que vedada a sua utilização.
\end{abstract}

Palavras-chave: Progressão continuada. Avaliação. Ensino Fundamental.

\section{CONTINUED PROGRESSION AND EVALUATION METHOD IN A STATE SCHOOL IN HUMAITÁ - AM CITY}

\section{ABSTRACT}

The Education Guidelines and Bases Law (brasilian LDB) No. 9,394/96 provides in Article $32 \S 2^{\circ}$ for school institutions to use the Continued Progression method, which is directly linked to evaluation. The research aims to demonstrate statistically and descriptively the reality of the evaluation in the respective method, showing issues such as learning time, evaluative practices and individual monitoring from the perspective of the students with whom a research was carried out in the 9th grade of Elementary School II, at a State School in the Humaitá - AM city. Studies on the theme made it possible to identify the rights provided by law that served as the basis for our analysis, demonstrating that all evaluative forms are used in the classroom, however, there are still things of traditional teaching in the measures used, with students who want to wait by instructions and that the term "disapproval" is still present in the school context, even if its use is prohibited.

Keywords: Continued progression. Evaluation. Elementary School.

Recebido em: $19 / 2 / 2020$

Aceito em: $24 / 3 / 2020$

\footnotetext{
1 Licenciatura em Letras - Língua e Literatura Portuguesa e Inglesa pela Universidade Federal do Amazonas (2016). Com experiência na docência em Língua Inglesa no projeto CEL do IEAA/Ufam e no Centro Educacional Evangélico Betel (Ceeb). Mestranda do Programa de Pós-Graduação em Ensino de Ciências e Humanidades do Instituto de Educação Agricultura e Ambiente (IEAA). Atua no Centro Educacional de Tempo Integral Agostinho Ernesto de Almeida. http://lattes.cnpq.br/4211708381735482. https://orcid.org/0000-0003-3064-482X. daia.dianareis@gmail.com

2 Bacharelado em Administração de Empresas. Licenciatura em Filosofia. Mestrado em Sociedade e Cultura na Amazônia - Ufam - e Doutorado em Ciências Sociais pela Unicamp. Professor da Universidade Federal do Amazonas desde 2006, atuando na Área de Filosofia Geral e Filosofia da Educação, ministrando disciplinas em cursos de Graduação. Membro do Programa de Mestrado em Ensino de Ciências e Humanidades (PPGECH). Membro do Programa Graduação em Filosofia - Prof-Filo. Lotado no Instituto de Ciências Sociais, Educação e Zootecnia (ICSEZ) na cidade de Parintins-Amazonas. http://lattes.cnpq.br/4261012017955416. https://orcid.org/0000-0001-5205-9766. aldairufam@gmail.com
} 
A legislação educacional no Brasil tem por base princípios que são descritos por meio do texto constitucional e devem ser utilizados em situações atuais no desenvolvimento do ensino nas instituições escolares públicas e privadas. Esta é a Lei de Diretrizes e Bases da Educação (LDB) n 9.394/96 que, entre as várias especificações, prescreve no artigo $32, \S 2^{\circ}$, permissão às escolas para utilizar a Progressão Continuada. De acordo com Guilherme (2007), o Regime de Progressão Continuada (RPC) é o sistema político avaliativo que surgiu ante a necessidade de diminuição da retenção escolar e a possibilidade de oferecer aos cidadãos de classe baixa oportunidade de receber educação. Destaca-se ainda a avaliação no ensino da Língua Portuguesa, pois é a nossa língua materna e por meio dela há o desenvolvimento nos demais componentes curriculares.

O RPC está presente em todos os ciclos educacionais, pois em qualquer sistema educativo os alunos não devem estagnar, seja em uma série, um módulo, um semestre ou ciclo, uma vez que há sempre a necessidade de progressão e de desenvolvimento do aluno. No Brasil, pode ser encontrado que:

Art. 32. [...] § 20 Os estabelecimentos que utilizam progressão regular por série podem adotar no ensino fundamental o regime de progressão continuada, sem prejuízo da avaliação do processo de ensino-aprendizagem, observadas as normas do respectivo sistema de ensino (BRASIL, 2017, p. 23).

Desse modo é possível compreender que o uso do RPC é opcional, e pode ser adotado na íntegra ou parcialmente, oferecendo flexibilidade ao levar em conta a individualidade de cada região, situação econômica, social e cultural. Com isso cabe a cada unidade federativa definir se é viável sua efetivação nas instituições escolares a partir de suas políticas educacionais (JEFFREY, 2011).

Historicamente, o RPC está presente no contexto educacional desde 1871, em Paris. No Brasil, segundo Jeffrey (2011), sua adoção data de meados de 1920 inicialmente chamado de "Progressão Automática". Em sua origem é possível observar que o regime não estava preocupado com a qualidade da educação, mas em diminuir a taxa de reprovação e desistências nas escolas (FERREIRA, 2006). Com o decorrer dos anos, o uso do RPC passou por transformações, substituindo a preferência pelos dados estatísticos pela qualidade da educação. Atualmente, para que um aluno prossiga de um ano para o outro é necessário que seja avaliado adequadamente, cumprindo-se as disposições na legislação pertinente, entre as quais estão a presença de profissionais qualificados, plena condição de matrícula, aproveitamento de aprendizagem, recursos financeiros, ação didática e outros.

A avaliação é um dos principais sistemas de complementação do RPC, condição em que o educando não pode progredir sem ser avaliado adequadamente. A avaliação à qual nos referimos neste trabalho não se remete apenas àquela que qualifica o aluno por meio de notas, mas as diferentes formas e condições que buscam o desenvolvimento educacional do aluno.

O objetivo deste estudo é demonstrar descritiva e estatisticamente a realidade da avaliação no Regime de Progressão Continuada em uma Escola Estadual do Município de Humaitá/AM. Esta pesquisa foi pautada no estudo de autores como Brandão, Baeta 
e Rocha (1983), Bezerra (2015), Ferreira (2006) e Lorenzato (2008), e das legislações vigentes, visando a identificar como a avaliação é vista pelos alunos e como os seus direitos estão sendo postos em prática nas aulas de Língua Portuguesa.

\section{REGIME DE PROGRESSÃO CONTINUADA: História, Organização e Estrutura}

O RPC está presente no sistema educacional brasileiro desde 1998, a partir da Deliberação do Conselho Estadual de Educação no Estado de São Paulo (CEE-SP, 9/97). Esta organização prevista na Lei de Diretrizes e Bases da Educação Nacional (LBD) n.으 9.394/1996, surgiu, segundo Jeffrey (2011), como uma das soluções para o fracasso, repetência e evasão escolar. Estudos como os de Brandão, Baeta e Rocha (1983) revelaram à época que aos alunos estavam sendo imposta a seletividade social nas escolas, pois não havia comprometimento com as classes que necessitavam do sistema público de educação.

Entre as décadas de 70 e 80 o ensino estava pautado nas habilidades sociais e profissionais e não na aprendizagem dos alunos, o que resultava apenas em gastos exorbitantes aos cofres públicos, pois, por mais que houvesse investimento na educação, um número significativo de alunos completava seus estudos sem saber ler e escrever (BRANDÃO; BAETA; ROCHA, 1983). Com isso, surgiu a necessidade de mudanças no sistema educacional brasileiro, assim como ocorreu na França e na Inglaterra, que já haviam passado por situações semelhantes, em que os aluno e produto ainda estavam interligados. A realidade da educação no meio social precisava ser repaginada, visando, principalmente, ao comprometimento com camadas populares e com projetos de reformas educacionais (BEZERRA, 2015).

Inicialmente, o RPC foi intitulado "progressão automática" por Oscar Thompson e Sampaio Dória, os quais, influenciados pelos ingleses, buscavam aumentar o número de alunos nas instituições escolares (JEFFREY, 2011).

O fracasso escolar foi destaque a partir de 1950. Em congresso da Organização das Nações Unidas para a Educação, a Ciência e a Cultura (Unesco) o Brasil foi citado como exemplo de maior índice de retenção escolar e pouco investimento na educação (JEFFREY, 2011). Em conferência, Almeida Junior, representante brasileiro, expôs medidas que ajudariam a remediar a situação, entre elas destaca-se a utilização da progressão automática, uma medida imediata que aumentaria significativamente o número de alunos nas escolas. A partir desses problemas a primeira posição a ser tomada era adicionar ao regime um currículo com base no desenvolvimento dos educandos, o qual, sem seletividade e retenções, tornaria a instituição escolar formadora e educativa (JEFFREY, 2011).

Em decorrência disso, de acordo com Jeffrey (2011), a progressão automática foi instituída em escolas públicas nas cidades dos Estados de Pernambuco, Minas Gerais e São Paulo, entre outras. Os resultados da progressão, no entanto, demonstraram os mesmos problemas anteriores, isto é, o escamoteamento dos índices de reprovação era solucionado, mas problemas como resistência dos professores ao sistema (os quais estavam ligados ao sistema tradicional de retenção), falta de atendimento individual e desempenho insuficiente dos alunos permaneciam. 
Bezerra (2015) discorre que foi a partir desses resultados que, com influência internacional, surgiu a ideia da criação de ciclos de aprendizagem, em que se dividia os anos escolares, por exemplo, $1^{\circ}$ ciclo do $1^{\circ}$ ao $5^{\circ}$ ano, o $2^{\circ}$ ciclo, do $6^{\circ}$ ao $8^{\circ}$ ano. Desta forma, os alunos não mais seriam avaliados ao final de cada ano escolar, e sim ao fim de cada ciclo. A progressão continuaria presente, porém não a retenção, pois caso a passagem do aluno fosse vetada ao final do ciclo, este teria mais tempo para desenvolver seu aprendizado.

A utilização dos ciclos teve os mesmos resultados que os da progressão automática, apenas disfarçaram os índices negativos. Desta forma, o surgimento da primeira LDB n.o 9.394/1996 trouxe novas diretrizes que buscavam resolver os entraves presentes no meio educacional. A partir da instituição da lei, a utilização de ciclos permaneceu e a progressão automática passou a se chamar RPC.

Ambos continuam em vigência, sendo criadas novas diretrizes, e com o auxílio de dispositivos que regem as políticas avaliativas educacionais, DCNs (Diretrizes Curriculares Nacionais) e os PCNs (Parâmetros Curriculares Nacionais), deveriam ser obedecidas para que o avanço dos alunos estivesse constantemente atrelado ao seu crescimento educacional. Pode-se destacar a ampliação de horas-aula, mudanças na forma de avaliação, acompanhamento individualizado com o educando e a não utilização da retenção (reprovação).

Destaca-se como um problema do sistema educacional a indisponibilidade de tempo da escola para com os educandos, sendo, portanto, fundamental, ampliar as horas-aula nas instituições escolares.

A redução acentuada da carga horária impedia o desenvolvimento pleno nos componentes curriculares durante as aulas. Assim, a LDB dispõe que a carga horária anual mínima dos alunos na escola é de 800 horas, distribuídas por 200 dias letivos, sem considerar os dias destinados às provas finais (artigo 24, I.), dando importância ao tempo de aprendizado do aluno, que deve ser aproveitado ao máximo.

As formas de avaliação, por sua vez, não podem mais ser exclusivamente subjetivas ou objetivas, devendo "assumir um caráter processual, formativo e participativo, ser contínua, cumulativa e diagnóstica" (BRASIL, 2013, p. 123). As novas formas avaliativas podem ser encontradas nos artigos 12, 13 e 14 da LDB, os quais apontam para a importância da aprendizagem e os meios de recuperação para com os alunos de baixo rendimento, em que os resultados qualitativos teriam mais importância que os quantitativos.

O uso das avaliações subjetivas e objetivas com finalidade quantitativa impedia o progresso dos educandos, porque estes resultavam em prejulgamento, classificando-os sem analisar o conhecimento adquirido. Segundo Valente e Arelaro (2002) a avaliação que seguia o modelo de seriação contemplava o caminho da rigidez dos conteúdos. A organização do sistema seriado, é realizado através da progressão regular por séries, com conteúdos rígidos que servem como pré-requisito para as séries seguintes, e o rendimento da aprendizagem dos alunos deve ser verificado ao decorrer e ao final do ano letivo através de provas e exames. Desta forma o conhecimento era idealizado de forma linear, em que o currículo tinha início do "concreto para o abstrato, e do simples para o complexo", o que não se enquadra com a realidade da aprendizagem diária dos alunos, que por sua vez inicia-se de forma contrária, do abstrato para o concreto, por exemplo a aprendizagem da escrita, que tem como base a linguagem (VALENTE; ARELARO, 2002, p. 22). 
Em terceiro lugar, existe a questão do acompanhamento individualizado, pois se entende que, atualmente no Brasil, há muitos alunos que não têm acompanhamento em casa. A LDB dispõe no artigo 24 , parágrafo $V$, que as escolas têm a obrigação de oferecer ao aluno acompanhamento adequado com "tempos e espaço de recuperação" (BRASIL, 2017, p. 18) para estudantes com baixo rendimento escolar e, de preferência, que estas aulas ocorram no contraturno. Para Souza (1999), as novas medidas tornam o conhecimento um processo, em que o aluno se torna o foco principal e se forma continuamente.

Em quarto lugar está a não utilização da retenção (reprovação). A LDB, por meio do RPC, facilitou a permanência dos educandos na escola, flexibilizando o ensino. A partir da vigência do regime o currículo perdeu a rigidez. Termos avaliativos fixos como "aprovado" ou "reprovado" foram eliminados, ampliando as possibilidades da equipe docente, a qual deverá avaliar sem classificar, favorecendo a aprendizagem (VALENTE; ARELARO, 2002).

Valente e Arelaro (2002) ponderam que a reprovação não deve ser vista como um ponto positivo, uma vez que não garante qualidade de ensino. Para eles "a repetência não tem se constituído em alternativa social ou pedagógica para motivar ou garantir a aprendizagem dos alunos" (p. 23), ou seja, os alunos são mais propensos ao fracasso escolar caso submetidos à reprovação por fatores psicológicos. Desse modo, quando a escola utiliza a reprovação, limita-se apenas a transmitir informações, desconsiderando os demais aprendizados do aluno e os conhecimentos adquiridos nos demais componentes curriculares.

Para Camargo (1999), o Regime de Progressão Continuada busca universalizar a Educação Básica de modo a garantir que as crianças permaneçam na escola, substituindo a repetência pela inclusão. Tanto os professores quanto os alunos devem observar o regimento vigente na escola em que trabalham/estudam, pois a legislação age de forma distinta nos diferentes estados (BRASIL, 2017).

Jeffrey (2011) ressalta que com o uso do RPC a escola é forçada a encontrar diferentes maneiras de ensinar, assegurando a aprendizagem. Assim, os alunos que não atingem a média ao final de cada bimestre deverão ter um acompanhamento especial, sem repressões quanto a "reprovações" ou limitações de tempo, além de contar com um profissional que identifique as dificuldades de aprendizagem, reestruturando a metodologia de ensino e didática.

É essencial que se observe que a instituição do RPC se dá pelo conhecimento de suas diretrizes, haja vista que não há texto sem contexto, não é possível entender o RPC sem o estudo da legislação pertinente. Este trabalho identifica alguns pontos na legislação que complementam o RPC, contudo não pretende exaurir ou esgotar a discussão sobre o Regime.

\section{AVALIAÇÃO NO ENSINO DA LÍNGUA PORTUGUESA}

O desenvolvimento do ensino de Língua Portuguesa no ambiente educacional faz-se importante por ser o estudo da língua materna, utilizada na comunicação diária e na imposição crítica das situações cotidianas. O processo de ensino da Língua Portuguesa 
na escola era inicialmente pautado na gramática. Segundo Sena (2001), a teoria não era ensinada em conjunto com seu processo natural, que seria o da linguagem cotidiana dos alunos, e sim da norma padrão da língua, em que somente a escrita e o discurso formal eram relevantes.

A imposição da norma culta centralizada na gramática distancia pontos fundamentais, entre eles "a prática consciente e estruturada do discurso oral". De acordo com Sena (2001), o processo pedagógico que considera somente na gramática não proporciona o total domínio da linguagem (discursivo, cognitivo e simbólico) impedindo o desenvolvimento de plena participação nos variados segmentos sociais, pois seu conhecimento está focalizado em regras e não na habilidade de construir um discurso coerente.

Para Slobin (1980), o indivíduo pode conhecer o vocabulário de um idioma e, mesmo assim, não ter a capacidade de construir frases. Por isso, o ensino da Língua Portuguesa como componente curricular é obrigatório nas escolas e deve ser desenvolvido com o intuito de aperfeiçoar a linguagem e escrita dos alunos, tanto formal quanto informal, utilizando-se do bidialetalismo para se impor ante as situações vividas em qualquer grupo social e formulando seus próprios conceitos (LORENZATO, 2008).

Segundo os Parâmetros Curriculares Nacionais de Língua Portuguesa no Ensino Fundamental, o ensino e aprendizagem devem resultar de três variáveis, "o aluno, os conhecimentos com os quais se opera nas práticas de linguagem e a mediação do professor" (BRASIL, 1998, p. 22). O ensino de Língua Portuguesa está disposto na segunda variável e pautado nos seguintes requisitos:

No caso do ensino de Língua Portuguesa, considerar a condição afetiva, cognitiva e social do adolescente implica colocar a possibilidade de um fazer reflexivo, em que não apenas se opera concretamente com a linguagem, mas também se busca construir um saber sobre a língua e a linguagem e sobre os modos como as opiniões, valores e saberes são veiculados nos discursos orais e escritos. Tal possibilidade ganha particular importância na medida em que o acesso a textos escritos mais complexos, com padrões lingüísticos mais distanciados daqueles da oralidade e com sistemas de referência mais distantes do senso comum e das atividades da vida diária, impõe a necessidade de percepção da diversidade do fenômeno lingüístico e dos valores constituídos em torno das formas de expressão (BRASIL, 1998, p. 47).

Observa-se que o ensino da Língua Portuguesa é pautado, de acordo com os PCNs (BRASIL, 1998), na gramática e interpretação dos textos; por exemplo, as construções frasais não se relacionam somente com a sintaxe, mas igualmente ao fenômeno linguístico, que considera a situação em que o aluno se encontra e suas interpretações de mundo já vividas. As questões sociais e individuais são destacadas para que o professor possa melhorar sua prática pedagógica, pois não há como ensinar padrões complexos sem que os alunos já estejam previamente familiarizados com elas.

A visão dos PCNs (BRASIL, 1998) busca tornar o professor de Língua Portuguesa mediador, em que seu papel seria se dispor a selecionar momentos que façam os alunos utilizarem sua criticidade e reflexão. Esse avanço dar-se-á progressivamente, e com o passar do tempo os alunos poderão se desenvolver ante os conhecimentos mais específicos compreendendo-os de maneira complexa (BRASIL, 1998, p. 49). 
Assim, sabendo da importância de aprender a Língua Portuguesa, deve-se pôr em foco a avaliação, pois faz parte do cotidiano dos professores, destacando-se que o sistema busca identificar como está o andamento dos conhecimentos adquiridos pelos alunos. Entre os documentos que regem as políticas avaliativas educacionais atuais, podemos citar as DCNs (BRASIL, 2013) e os PCNs (BRASIL, 1998).

As DCNs são normas fixadas pelo Conselho Nacional de Educação (CNE) e têm base na LDB. Neste contexto, são obrigatórias na Educação Básica e devem orientar o planejamento curricular dos sistemas de ensino nas escolas. Em contraponto, os PCNs são diretrizes elaboradas pelo MEC, com seu uso sendo facultativo e utilizado para revisão curricular, o qual é dividido por disciplinas.

A avaliação, segundo as DCNs (BRASIL, 2013), deve ser pautada no currículo com estratégias para os alunos que apresentarem baixo rendimento, considerando os "aspectos qualitativos sobre os quantitativos" (p. 123), e os resultados não devem considerar somente o resultado das provas finais, mas os identificados durante todo o ano letivo. As DCNs (BRASIL, 2013) dispõem que a avaliação deve ser realizada pelo educador em conjunto com a escola e a ação pedagógica "deve assumir um caráter processual, formativo e participativo, ser contínua, cumulativa e diagnóstica" (ibid).

Os princípios avaliativos visam a identificar as dificuldades dos alunos de modo a saná-las e quando necessário intervir imediatamente para que os alunos continuem progredindo em seus estudos. A avaliação contínua, por seu turno:

Pode assumir várias formas, tais como a observação e o registro das atividades dos alunos, sobretudo nos anos iniciais do Ensino Fundamental, trabalhos individuais, organizados ou não em portfólios, trabalhos coletivos, exercícios em classe e provas, dentre outros. Essa avaliação constitui um instrumento indispensável do professor na busca do sucesso escolar de seus alunos e pode indicar, ainda, a necessidade de atendimento complementar para enfrentar dificuldades específicas, a ser oferecido no mesmo período de aula ou no contraturno, o que requer flexibilidade dos tempos e espaços para aprender na escola e também flexibilidade na atribuição de funções entre o corpo docente (BRASIL 2013, p. 123).

As DCNs (BRASIL, 2013) orientam para a necessidade de utilização de formas avaliativas diversas, destacando-se os registros que irão ajudar os professores a se manterem atualizados quanto ao progresso dos alunos. Além disso, faz-se necessário manter estes registros disponíveis para quando necessário, possam ser utilizados por educadores, como informções para auxílio dos educandos.

Outro ponto de igual pertinência é a disponibilidade de aulas no contraturno, pois as DCNs são baseados na LDB e entende-se que existe a concepção de que o ensino não deve se limitar ao tempo. Com isso, os educandos podem receber atendimento complementar, se necessário, para esclarecer suas dúvidas e questionamentos, observando-se que estas devam ocorrer em horário de aula ou em contraturno, por isso devendo dispor a escola de espaço para uma possível recuperação como determina a LDB. 
Com relação aos PCNs (BRASIL, 1998), considera-se central a explanação relativa ao Ensino Fundamental no componente curricular de Língua Portuguesa, pelo fato de exercer uma postura reflexiva sobre a prática pedagógica, buscando contribuir no desenvolvimento e no planejamento das aulas. No componente curricular de Língua Portuguesa os PCNs consideram os seguintes critérios:

Demonstrar compreensão de textos orais, nos gêneros previstos para o ciclo [...]; Atribuir sentido a textos orais e escritos, posicionando-se criticamente diante deles. Ler de maneira independente textos [...]; Compreender textos a partir do estabelecimento de relações entre diversos segmentos do próprio texto, entre o texto e outros diretamente implicados por ele; Selecionar procedimentos de leitura adequados a diferentes objetivos (estudo, formação pessoal, entretenimento, realização de tarefa) e a características do gênero e suporte; Coordenar estratégias de leitura não lineares utilizando procedimentos adequados para resolver dúvidas na compreensão e articulando informações textuais com conhecimentos prévios; Produzir textos orais nos gêneros previstos para o ciclo [...] Redigir textos na modalidade escrita nos gêneros previstos para o ciclo, considerando as especificidades das condições de produção; Escrever textos coerentes e coesos, observando as restrições impostas pelo gênero; Redigir textos utilizando alguns recursos próprios do padrão escrito[...]; Escrever textos sabendo utilizar os padrões da escrita, observando regularidades lingüísticas e ortográficas; Revisar os próprios textos com o objetivo de aprimorá-los; Utilizar os conceitos e procedimentos constituídos na prática de análise linguística (BRASIL, 1998, p. 95-98).

Os critérios avaliativos descritos devem ser considerados no contexto em que o objetivo é conduzir a um ensino significativo. Para isso, os PCNs (BRASIL, 1998) dispõem a respeito do papel da avaliação na prática avaliativa, e esta dve ser construtiva, reflexiva e considerar os aspectos sociais e culturais em que vive o educando. A reflexiva ajudará na autonomia do aluno e na oportunidade de busca de informações que utilizará em sua prática pedagógica. A construtiva possibilitará que o aluno realize uma autoavaliação a ponto de se conscientizar da necessidade de adquirir conhecimentos, e ao educador na análise de informações coletadas sobre a aprendizagem dos alunos, auxiliando-o em uma possível ação pedagógica. Para considerar os aspectos sociais e culturais é necessário compreender que a avaliação não deve ser parcial, ou seja, considerando apenas o estudante, mas crie espaço de ensino e aprendizagem a partir do diálogo entre o aluno e o professor (BRASIL, 1998).

Verificamos que é complexa a construção de uma prática avaliativa mediadora, que identifique uma aprendizagem construtiva e significativa. O processo é longo, e deve ser analisado com cautela, pois a avaliação que busca desenvolver a aprendizagem deve transpor-se ao tradicional (processo de avaliação que verifica o aprendizado do aluno através de notas em provas e exames), não limitando-se somente a gramática ou ao discurso (HOFFMANN, 2001).

\section{LEGISLAÇÃO EDUCACIONAL NAS ESCOLAS ESTADUAIS DO MUNICÍPIO DE HUMAITÁ/AM}

No município de Humaitá-AM, a Secretaria de Estado de Educação (Seduc) cumpre as determinações do Conselho Estadual de Educação (CEE), que na resolução no $48 / 2015$, orienta que os regimentos devam ser cumpridos, estabelecendo como deve 
ocorrer o processo avaliativo nas escolas, como devem ser pontuadas as avaliações, a quantidade de avaliações que serão efetivadas durante o bimestre e os instrumentos de avaliação.

A resolução do CEE (2015), no capítulo IV, artigo 70, orienta que as escolas admitam a Progressão apenas parcialmente. As escolas estaduais de Humaitá-AM dispõem da prerrogativa de utilizar a Progressão Continuada nos anos iniciais no Ciclo I e no Ciclo II, enquanto no ciclo III deverá adotar o Regime de Progressão Continuada de modo parcial.

Ao se aplicada a Progressão parcialmente implica que os alunos só serão avaliados ou retidos no final do ciclo, ou seja, no final do ciclo I, II e III. No sentido de evitar a retenção o CEE (AMAZONAS, 2015) propõe que os alunos passem, primeiramente, pelas atividades avaliativas propostas pelos professores no decorrer do ano; se não conseguirem alcançar o desenvolvimento suficiente, deverão realizar uma recuperação final; se ainda assim não alcançarem a média, deverão seguir para o Conselho de Classe (reunião com professores que avalia se o aluno tem as competências e habilidades necessárias para passar à série seguinte). Se não aprovado no Conselho de Classe deverá ascender ao ano seguinte com pendência no componente curricular no qual não alcançou média final, isto é, o aluno fica pendente apenas nas matérias em que não alcançou a média final (CEE, Cap. IV, artigo 70, §4), constituindo direito dele realizar a recuperação de estudos com acompanhamento especial e diferenciado com os professores no horário de contraturno (CEE, Cap. IV, artigo 70, §2).

\section{METODOLOGIA}

Iniciamos este estudo com uma pesquisa referencial detalhada sobre o RPC e a avaliação no componente curricular de Língua Portuguesa, com estudos previstos em lei a partir das concepções de autores que possibilitassem o desenvolvimento crítico e descritivo do trabalho.

Realizamos para a coleta de dados uma pesquisa de campo no mês de julho de 2019 em uma escola estadual do município de Humaitá/AM. Participaram da pesquisa alunos do $9^{\circ}$ ano, nas aulas do componente curricular de Língua Portuguesa. Essa turma foi selecionada porque se entende que seus integrantes possuem ampla carga de experiência, podem fazer correlações e avaliações sobre diversas situações no ambiente escolar. A pesquisa foi realizada durante os turnos matutino e vespertino em três turmas do $9^{\circ}$ ano, com aproximadamente 55 alunos matriculados. Do grupo pesquisado, somente 28 tiveram autorização de participação assinada por pais ou responsáveis.

A pesquisa é do tipo survey, que de acordo com os autores Pinsonneault e Kraemer (1993), permite dar amplitude na obtenção dos dados coletados, possibilitando acesso ao modo de pensar e se comportar dos entrevistados e demais aspectos peculiares. O objetivo principal do método é obter por meio de um instrumento já determinado, como um questionário, informações quantitativas mediante o estudo de um fenômeno natural, o caso da atual pesquisa, que deriva de acontecimentos cotidianos do ambiente escolar. 
Para a coleta de dados foram utilizados questionários com a escala Likert, a qual, segundo Backer (1995), fornece aos entrevistados respostas uniformes para as questões previamente propostas. No questionário foram utilizadas 19 questões fechadas e estabelecidos cinco pontos como alternativa de resposta: (1) discordo totalmente; (2) discordo parcialmente; (3) indiferente; (4) concordo parcialmente e (5) concordo totalmente (VIEIRA, 2009).

Para a análise dos resultados dos questionários estatísticos e descritivos foi calculada a quantidade de respostas (QR), dividida pelo número de participantes (NP), o que nos proporcionou o percentual de respostas (PR): $Q R /{ }_{N P}=\mathrm{PR}$ ). Definida a porcentagem para cada alternativa de resposta, foi possível identificar o ponto de vista dos alunos, o que permitiu a presente análise.

As afirmativas foram divididas em cinco tabelas agrupadas com o mesmo assunto em questão. As análises das tabelas foram baseadas em estudos sobre RPC observando os seguintes pontos: ampliação de horas-aula, mudanças na forma de avaliação, acompanhamento individualizado com o educando e a não utilização da retenção (reprovação). Estes dados foram identificados anteriormente e conduzirão a discussão para entendermos o RPC e seu contexto em sala de aula.

\section{RESULTADOS E DISCUSSÕES}

Destaca-se nesta pesquisa o RPC, a sua aplicação em situações reais e como é desenvolvido em uma escola do município de Humaitá/AM. O RPC é um sistema que não pode ser confundido com a Progressão Automática, fazendo-se necessário compreender que ele busca ajudar o aluno no seu desenvolvimento educacional, pessoal, crítico, ético, psicológico e profissional.

O RPC está continuamente ligado à avaliação escolar. Com isso, é importante destacar que o sistema em si não deve ser visto como um regime de "progressão automática", considerado apenas no final do ano e que aprova o aluno de uma série para a outra. Muito além disso, deve ser trabalhado por meio das avaliações diárias, utilizando a legislação a seu favor, pois nela estão os direitos dos alunos que complementam o regime. Assim, o RPC não pode ser tratado somente como "reprovação" ou "aprovação" do aluno, mas deve verificar se este está recebendo uma educação de qualidade, se há tempo disponível por parte dos docentes para ajudá-lo em suas dúvidas e se o ensino ofertado condiz com o que propõe a lei.

Do grupo pesquisado $75 \%$ dos participantes são do sexo feminino e $25 \%$ do sexo masculino. Diante das respostas obtidas, percebeu-se que os estudantes percorreram todas as escalas de 1 a 5, possibilitando resultados significativos para esta discussão.

A Tabela 1 é resultante das questões que versam sobre a opinião dos discentes sobre o período escolar em que estão matriculados, como pode ser identificado a seguir. 
Tabela 1 - Período Escolar

\begin{tabular}{|c|c|c|c|}
\hline Pontos & PR Afirmativa 1 & PR Afirmativa 2 & PR Afirmativa 3 \\
\hline 1 & $14 \%$ & $53 \%$ & $3 \%$ \\
\hline 2 & $14 \%$ & - & $14 \%$ \\
\hline 3 & $17 \%$ & $14 \%$ & $10 \%$ \\
\hline 4 & $14 \%$ & $3 \%$ & $21 \%$ \\
\hline 5 & $39 \%$ & $28 \%$ & $50 \%$ \\
\hline
\end{tabular}

Fonte: Os autores (2020).

A afirmativa 1 foi apresentada da seguinte forma: "A minha escola utiliza a educação em tempo matutino/vespertino, em que há múltiplas oportunidades de aprendizado através de um programa político-pedagógico, pois é possível o contato com as atividades culturais, artes, esportes, ciência e tecnologia, tanto na prática quanto na teoria". De acordo com as respostas obtidas foi possível identificar que $14 \%$ dos alunos discordam totalmente, $14 \%$ discordam parcialmente, $14 \%$ concordam parcialmente, $39 \%$ concordam totalmente e $17 \%$ dos alunos foram indiferentes à afirmativa. Neste contexto, é possível perceber que apesar de a maioria concordar que o ensino nos turnos matutino ou vespertino proporciona diversas oportunidades de conhecimentos, há uma grande parcela que se mostra indiferente e outra que discorda, o que pode gerar a identificação com o ensino integral ou com uma maior quantidade de aulas.

Tendo em vista que os alunos poderiam se identificar de alguma forma com o ensino integral e que os ajudaria a melhorar sua educação de modo a estarem preparados para as avaliações futuras, como os vestibulares, foram formuladas as afirmativas 2 e 3 a fim de identificarmos a questão do tempo e a qualidade de educação. A afirmativa 2 dispõe: "Com o ensino em tempo integral, acredito ter uma base de aprendizado sólida no componente curricular de Língua Portuguesa que me ajudará em avaliações futuras, como vestibular e Exame Nacional do Ensino Médio (Enem)".

Observou-se que $53 \%$ dos discentes não acreditam que a quantidade de tempo de estudo resulte em um aprendizado sólido, enquanto $3 \%$ concordam parcialmente e $28 \%$ concordam completamente que essas questões são importantes e 14\% mostraram-se indiferentes.

Em contrapartida, a afirmativa 3, discorre: "Com o ensino em tempo matutino/vespertino, acredito ter uma base de aprendizado sólida no componente curricular de Língua Portuguesa que me ajudará em avaliações futuras, como vestibular e Enem". Conforme a Tabela 1, $3 \%$ discordam completamente e $14 \%$ discordam parcialmente, $21 \%$ concordam parcialmente, $50 \%$ concordam completamente e $10 \%$ foram indiferentes à alternativa. Compreende-se, portanto, que, de acordo com a maioria dos alunos, o tempo não está relacionado à qualidade da educação e no seu desenvolvimento em avaliações futuras, deixando claro sua preferência por apenas um turno de aula.

A segunda tabela, disposta a seguir, contém perguntas relacionadas ao quesito de avaliação, para compreender como está o andamento do sistema avaliativo utilizado pelos professores na escola. 
Tabela 2 - Sistema Avaliativo

\begin{tabular}{|c|c|c|c|c|}
\hline Pontos & PR Afirmativa 4 & PR Afirmativa 5 & PR Afirmativa 6 & PR Afirmativa 7 \\
\hline 1 & - & $14 \%$ & - & $10 \%$ \\
\hline 2 & $10 \%$ & $7 \%$ & $21 \%$ & $14 \%$ \\
\hline 3 & $14 \%$ & $39 \%$ & $35 \%$ & $28 \%$ \\
\hline 4 & $10 \%$ & $14 \%$ & $28 \%$ & $10 \%$ \\
\hline 5 & $64 \%$ & $25 \%$ & $14 \%$ & $32 \%$ \\
\hline
\end{tabular}

Fonte: Os autores (2020).

Assim, a afirmativa 4 foi projetada da seguinte forma: "As avaliações de Língua Portuguesa são objetivas e subjetivas e enfatizam a participação do trabalho em grupo". Neste sentido, $10 \%$ dos alunos discordam parcialmente da afirmativa, $10 \%$ concordam parcialmente, $64 \%$ concordam completamente e $14 \%$ se mostraram indiferentes à questão. A maioria dos alunos acredita que as aulas de Língua Portuguesa são realmente diversificadas e percebe-se que não há respostas totalmente negativas, contudo deve haver pontos a serem melhorados em sala de aula para que as aulas possam ser bem mais aproveitadas.

Já a afirmativa 5 teve a função de contrapor a questão 4, formulada da seguinte maneira: "As avaliações de Língua Portuguesa são apenas objetivas e subjetivas". Desse modo, $14 \%$ discordam complemente, $7 \%$ discordam parcialmente que nas aulas de Língua Portuguesa são utilizadas somente avaliações objetivas e subjetivas, $14 \%$ concordam parcialmente, $25 \%$ concordam completamente que as avaliações em sala de aula sejam realizadas desta forma e $39 \%$ se mostraram indiferentes à afirmativa.

A variedade de respostas, o número de alunos que concordam com a afirmativa e mais a soma dos que são indiferentes à questão, permitiram refletir que as avaliações, em sua forma tradicional, podem ainda fazer parte do cotidiano escolar. Os resultados da questão 5 e da questão 4, quando relacionados, mostram que as atividades participativas estão sendo realizadas, mas quanto às avaliações serem objetivas e subjetivas os resultados divergiram. Isso deve-se ao fato da existência da predominância de avaliações focadas em índices de aprovação. Desse modo, a oportunidade de usar diversos tipos de avaliação é concedida ao professor, porém as avaliações tradicionais ainda são utilizadas por alguns profissionais, os quais transformam o conhecimento em uma unidade de medida, que resultará em dados estatísticos, numerologia frequentemente vista nos noticiários que demonstram a evolução da educação no país.

A afirmativa 6 foi formulada para que os alunos pudessem expor a situação em sala de aula e quais suas concepções sobre o modo que são avaliados: "Em minha escola o processo de avaliação no componente curricular não é apenas uma forma de julgamento de valor sobre o aproveitamento do aluno". Segundo as respostas, $21 \%$ discordam parcialmente, $28 \%$ concordam parcialmente, $14 \%$ concordam completamente e $35 \%$ se mostram indiferentes à questão.

Nenhum dos alunos concordou completamente, o que é um sinal positivo de que os professores estão utilizando mecanismos avaliativos que estimulam o aprendizado de seus alunos, contudo a porcentagem de estudantes indiferentes foi alta, o que se deve ao fato de os discentes não estarem atentos a essas questões. Nesse sentido, o ensino 
tradicional pode estar enraizado não somente no educador, mas também no educando. A "obediência" ainda está presente na mente dos alunos, pois se não conseguem identificar como está sendo realizado o processo de ensino, é possível que estejam apenas seguindo ordens.

A obediência excessiva limita seu desenvolvimento educacional, e é fácil encontrar alunos com dificuldade de desenvolver sua própria autonomia no aprendizado, pois seguir regras traz comodidade. As avaliações tradicionais que eram pautadas na memorização, por exemplo, revelam que os alunos apenas transferiam automaticamente as respostas dos livros didáticos, não havia uma discussão sobre o que era estudado, ou uma reflexão para então gerar a interpretação, a avaliação era mecanizada. Esta dificuldade deve ser tratada de forma significativa e direcionada pelos educadores, que conduzirão os alunos, por meio do diálogo, a construir suas próprias opiniões, contrapondo ideias e formando diferentes ideologias e não apenas a obedecer, ajudando-o a construir uma visão crítica e contextualizada sobre a situação atual por ele vivenciada.

As avaliações em sala de aula não devem ser se limitar a termos como "aprovado" ou "reprovado", tendo em vista que atualmente há outras formas de verificar no âmbito escolar, por exemplo, a utilização de diagnósticos que visem à aprendizagem plena do aluno. Deste modo, partiremos para a afirmativa 7, a qual foi baseada nos DCNs e dispõe: "As avaliações assumem caráter processual, cumulativo e participativo, contínua, cumulativa e diagnóstica". De acordo com os educandos, $10 \%$ discordam completamente e $14 \%$ parcialmente da afirmativa, $10 \%$ concordam parcialmente, $32 \%$ concordam completamente e $28 \%$ foram indiferentes à questão. Os termos dispostos aos alunos geraram muitos questionamentos, por isso foi necessária a intervenção da professora titular, que destinou um tempo para explicar sobre os tipos de avaliação. Pela variedade de respostas, todavia, foi possível identificar que o não conhecimento dos termos gerou dúvidas, mas a maioria dos alunos conseguiu reconhecer essas concepções de avaliação nas aulas do componente curricular de Língua Portuguesa.

Em decorrência disso, fez-se necessário destacar a seguir os quesitos tempo e auxílio nas práticas avaliativas, com os resultados dispostos a seguir.

Tabela 3 - Avaliação, Tempo de Aprendizagem e Acompanhamento

\begin{tabular}{|c|c|c|c|c|c|}
\hline Pontos & $\begin{array}{c}\text { PR } \\
\text { Afirmativa 8 }\end{array}$ & $\begin{array}{c}\text { PR } \\
\text { Afirmativa 9 }\end{array}$ & $\begin{array}{c}\text { PR } \\
\text { Afirmativa 10 }\end{array}$ & $\begin{array}{c}\text { PR } \\
\text { Afirmativa 11 }\end{array}$ & $\begin{array}{c}\text { PR } \\
\text { Afirmativa 12 }\end{array}$ \\
\hline 1 & $7 \%$ & $14 \%$ & $7 \%$ & $28 \%$ & $28 \%$ \\
\hline 2 & $17 \%$ & - & $7 \%$ & $3 \%$ & $21 \%$ \\
\hline 3 & $25 \%$ & $7 \%$ & $21 \%$ & $21 \%$ & $21 \%$ \\
\hline 4 & $10 \%$ & $42 \%$ & $7 \%$ & $10 \%$ & $7 \%$ \\
\hline 5 & $39 \%$ & $32 \%$ & $57 \%$ & $35 \%$ & $21 \%$ \\
\hline
\end{tabular}

Fonte: Os autores (2020).

O conhecimento e o tempo devem ser aliados, e, neste sentido, é importante que os alunos tenham disponibilidade de tempo e ajuda em sala de aula. Por este motivo a afirmativa 8 foi apresentada da seguinte forma: "Consigo sanar com facilidade todas as minhas dúvidas sobre os conteúdos do componente curricular de Língua Portuguesa durante o ano escolar". Nessa afirmativa as repostas foram divergentes, pois $7 \%$ dos 
alunos discordam completamente e $17 \%$ discordam parcialmente da afirmativa, $10 \%$ concordam parcialmente, $39 \%$ concordam completamente e $25 \%$ mostraram-se indiferentes.

A quantidade de estudantes que concordam é considerável, o que equivale ao entendimento de que o professor auxilia ao máximo nas dúvidas, contudo o número de discordâncias e indiferenças reflete dois pontos cruciais no ensino. A primeira refere-se a falta de liberdade dos alunos em se expressar, perguntar, ou fazer questionamentos que esclareçam suas dúvidas sobre os conteúdos apresentados e o segundo que o tempo do educador tende a ser limitado, ou seja, o professor consegue, na medida em que o tempo permite, atender grande parte dos alunos, porém há uma parcela significativa de alunos que não conseguem fazer parte deste momento e assim não lhes é dada a oportunidade de sanar suas dúvidas e dificuldades.

A afirmativa 9, por sua vez, era identificar, na visão dos alunos, se o tempo em sala de aula era suficiente para um aprendizado significativo. A questão foi apresentada desta forma: "Atualmente o professor do componente curricular de Língua Portuguesa dispõe de aproximadamente 50 minutos de aula. Este tempo possibilita ao aluno um aprendizado significativo que o ajudará futuramente a desenvolver textos críticos como, por exemplo, as redações nas provas do Enem". As respostas demonstraram que 14\% dos alunos discordam completamente da afirmativa, 42\% concordam parcialmente, $32 \%$ concordam completamente e $7 \%$ se mostraram indiferentes à afirmativa. Pode-se verificar que a maioria dos estudantes concorda que o tempo de aulas de Língua Portuguesa é suficiente em sala de aula. Conforme as observações realizadas na escola, identifica-se que as aulas deste componente curricular ocorrem quase todos os dias da semana, com 5 períodos, a maior carga horária de uma disciplina, possibilitando assim um melhor comprometimento com o ensino e compreensão dos alunos.

As afirmativas 10 e 11, presentes na Tabela 3, não estão relacionadas diretamente ao quesito tempo, mas sim à qualidade e quantidade, ou seja, se há necessidade de mais profissionais qualificados para auxiliar os professores. A partir dos estudos sobre os DCNs foi formulada a afirmativa 10, a qual dispõe: "Apenas um(a) professor(a) titular é o bastante para sanar as dúvidas sobre os conteúdos do componente curricular de Língua Portuguesa em minha sala de aula". Nesse quesito, 7\% dos alunos discordam completamente e 7\% discordam parcialmente que um professor é o bastante para sanar suas dúvidas em sala de aula; já $7 \%$ concordam parcialmente e $57 \%$ concordam completamente que um professor pode fazer este trabalho e $21 \%$ se mostraram indiferentes à questão. De acordo com os alunos, um professor de Língua Portuguesa é o suficiente, não sendo necessária a atuação de mais de um profissional em sala. Deste modo, com poucas respostas negativas, entende-se que os alunos se identificam com seus professores e sentem-se à vontade com a figura deles em sala de aula.

A afirmativa 11 foi apresentada a fim de complementar e entender as respostas da afirmativa anterior, identificando se os alunos já vivenciaram situações em que houvesse auxiliares que ajudassem o professor titular, com a seguinte afirmativa: "Além do professor titular dispomos da ajuda de outros profissionais que nos auxiliam no componente de Língua Portuguesa". Conforme apresentado na Tabela 3, 28\% dos alunos discordam completamente e $3 \%$ discordam parcialmente da afirmativa, ou seja, a maio- 
ria que discordou podem nunca ter tido acesso a esses profissionais, $10 \%$ concordam parcialmente e $35 \%$, concordam completamente com a afirmativa, o que revela que em algum momento esses alunos tiveram a oportunidade de ter esse acompanhamento extra, e $21 \%$ foram indiferentes à questão.

Algo que se destaca na afirmativa 11 é o número de indiferentes. Uma questão a ser ressaltada é que há muitos projetos de Língua Portuguesa de universidades na escola pesquisada, com profissionais qualificados que partilham seus conhecimentos, mas nem sempre esses projetos são voltados ao que está sendo ensinado. No decorrer da pesquisa foram realizadas intervenções na escola em estudo, porém com conteúdos diferentes dos que estavam sendo estudados, ou seja, as alternativas marcadas como indiferentes podem estar relacionadas ao acompanhamento direcionado a outros conteúdos.

A afirmativa 12 dispõe a respeito da qualidade de ensino, se verdadeiramente a escola disponibiliza atendimentos em contraturno, caso o aluno necessite: "Em minha escola, se um aluno sente dificuldades no componente curricular de Língua Portuguesa, este recebe atendimento complementar oferecido no mesmo período de aula ou no contraturno". Entre as respostas, $28 \%$ dos alunos discordam completamente da afirmativa, enquanto $21 \%$ discordam parcialmente que isto seja verdade, $21 \%$ se revelam indiferente à afirmativa, $7 \%$ concordam parcialmente e $21 \%$ concordam completamente. Os resultados revelam que $21 \%$ dos educandos não reconhecem desse tipo de atendimento, alguns alunos podem nunca ter presenciado, os outros $21 \%$, por sua vez, por se mostrarem indiferentes podem ter tido acompanhamento, mas com outros focos, como os projetos na escola, na qual há profissionais que ajudam os alunos, mas os conteúdos ministrados não são os ensinados em sala de aula.

As Tabelas 4 e 5 foram construídas para entendermos se ainda havia "reprovação" no ambiente educacional.

Tabela 4 - Reprovação e Avaliação

\begin{tabular}{|c|c|c|c|}
\hline Pontos & PR Afirmativa 13 & PR Afirmativa 14 & PR Afirmativa 15 \\
\hline 1 & $3 \%$ & $64 \%$ & $75 \%$ \\
\hline 2 & $7 \%$ & $10 \%$ & $7 \%$ \\
\hline 3 & $3 \%$ & $10 \%$ & $7 \%$ \\
\hline 4 & $7 \%$ & - & - \\
\hline 5 & $78 \%$ & $7 \%$ & $10 \%$ \\
\hline
\end{tabular}

Fonte: Os autores (2020).

Na afirmativa 13 (Tabela 4) havia a seguinte afirmativa: "Em minha escola, se um aluno não conseguir alcançar notas preestabelecidas pelo professor até o final do ano, há reprovação". Deste modo, 3\% dos alunos discordam totalmente da afirmativa e 7\% discordam parcialmente que exista reprovação no componente curricular de Língua Portuguesa, enquanto $7 \%$ concordam parcialmente, $78 \%$ concordam completamente e acreditam que ainda há reprovação e $3 \%$ se mostraram indiferentes. A maior parte dos 
respondentes afirmou que ainda há reprovação, mas para isso foi necessário identificar se havia alunos que já tinham chegado a esta posição, assim entram em foco as afirmativas 14 e 15.

A afirmativa 14 dispunha: "Já fiquei pendente no componente curricular de Língua Portuguesa bimestralmente". As respostas mostram que $64 \%$ dos alunos discordam completamente e $10 \%$ discordam parcialmente da afirmativa, $10 \%$ se mostraram indiferentes e $7 \%$ concordam completamente, o que revela que $7 \%$ dos alunos já ficaram pendentes bimestralmente, pois ninguém marcou concordo parcialmente.

Assim, partimos para a afirmativa 15, que destacava: "Já fiquei pendente no componente curricular de Língua Portuguesa anualmente". Para esta afirmativa as respostas foram diferentes, $75 \%$ dos discentes discordam totalmente e $7 \%$ discordam parcialmente, $7 \%$ se mostraram indiferentes e $10 \%$ concordam completamente. A parcela dos que já ficaram pendentes no ano foi maior dos que ficaram pendentes bimestralmente, ou seja, os números revelam que estes já podem ter passado por tal situação, enquanto a porcentagem de alunos que diz existir a reprovação (afirmativa 13), sabe por meio de situações já vividas que é possível haver reprovação.

Por entender que o termo reprovação não deveria mais existir, há uma última tabela com perguntas sobre possíveis retenções do aluno no componente curricular de Língua Portuguesa.

Tabela 5 - Avaliação Final no RPC

\begin{tabular}{|c|c|c|c|}
\hline Pontos & PR Afirmativa 16 & PR Afirmativa 17 & PR Afirmativa 18 \\
\hline 1 & $53 \%$ & $21 \%$ & $32 \%$ \\
\hline 2 & - & - & $7 \%$ \\
\hline 3 & $17 \%$ & $21 \%$ & $21 \%$ \\
\hline 4 & $21 \%$ & $10 \%$ & $10 \%$ \\
\hline 5 & $42 \%$ & $46 \%$ & $28 \%$ \\
\hline \multicolumn{2}{r}{ Fonte: Os autores (2020). } \\
\hline
\end{tabular}

A afirmativa 16 foi estabelecida a partir dos estudos vivenciados em sala de aula e os relatos dos professores de Língua Portuguesa, que dispõe: "Ao final do ano, se um aluno fica pendente no componente curricular de Língua Portuguesa há apenas uma avaliação para que este recupere o ano letivo". Essa avaliação refere-se à avaliação final, à qual o aluno tem direito e é prevista em lei; neste sentido, 53\% discordam totalmente, $21 \%$ concordam parcialmente, $42 \%$ totalmente e $17 \%$ se mostraram indiferentes à questão, ou seja, a maioria discorda que há apenas uma avaliação, mas há uma parcela de estudantes que concorda que esta é realizada. Isto leva à reflexão acerca de como essa avaliação é aplicada aos alunos. Observando que as respostas foram altas aos extremos (concordo e discordo) é possível que os educandos tenham dúvidas quanto à forma como é aplicada esta avaliação escolar.

A partir das possíveis dúvidas que poderiam surgir na análise, foi construída a questão 17, pois a avaliação não deve ser resultado apenas de uma prova, mas por meio de um diagnóstico adequado, se identificadas dificuldades de aprendizado, recapitular os conteúdos com novas didáticas para que assim o aluno possa prosseguir com 
seus estudos. Desse modo, para compreensão desta realidade foi apresentada a seguinte afirmativa: "Ao final do ano, se um aluno fica pendente no componente curricular de Língua Portuguesa há revisão dos conteúdos com o professor de Língua Portuguesa e posteriormente uma avaliação para que este recupere o ano letivo".

Logo, esta afirmativa nos permite entender se o acompanhamento previsto em lei estava presente antes das avaliações finais: entre as respostas $21 \%$ dos alunos discordam completamente da afirmativa, ou seja, para eles essas aulas não aconteciam, $21 \%$ se mostraram indiferentes, $10 \%$ concordam completamente e $46 \%$ concordam parcialmente, isto é, essas aulas acontecem e estão presentes antes da avaliação.

A última afirmativa a ser analisada é a que reflete como deveria ser seguido o RPC, se não há limitações de tempo o aluno deveria prosseguir nos estudos, mas com a oportunidade de ter mais tempo de ensino no componente curricular no qual tem mais dificuldade de aprendizagem. Assim, a afirmativa, diz o seguinte: "Ao final do ano, se um aluno fica pendente no componente curricular de Língua Portuguesa, mesmo depois de todas as tentativas de aprovação, este é encaminhado para o ano seguinte com pendência nesta matéria. Deste modo, não perde o ano letivo e estuda as matérias daquele ano e mais a matéria pendente de Língua Portuguesa com direito a aulas no contraturno e acompanhamento individual." De acordo com as respostas, 32\% discordam completamente e $7 \%$ discordam parcialmente que isto aconteça, $21 \%$ se mostraram indiferentes, revelando não reconhecerem esse tipo de avaliação na escola, 10\% concordam parcialmente e $28 \%$ concordam completamente com a afirmativa, indicando que as avaliações seguem esta sequência.

\section{CONSIDERAÇÕES FINAIS}

A presente pesquisa realizada em uma escola estadual com alunos do $9^{\circ}$ ano do Ensino Fundamental II, no município de Humaitá/AM, buscou descobrir como está sendo aplicado o RPC atualmente. Entendendo que este regime não deve ser visto como um processo automático, mas utilizado de acordo com as diretrizes dispostas na lei educacional vigente, foi possível identificar pontos importantes que conduziram este estudo, como a ausência de limitação de tempo ao ensino, pois cada aluno tem seu próprio tempo de aprendizagem, a presença de diferentes formas avaliativas, como a processual, formativa, participativa, contínua, cumulativa e diagnóstica, e se estas formas ainda são utilizadas como um processo de julgamento do aluno levando a eventuais "reprovações" no final do ano escolar.

Esta discussão não foi realizada de forma isolada, mas a partir de uma pesquisa de campo que resultaria em dados para uma dissertação de Mestrado. Dessa forma, foram utilizados estudos prévios que possibilitaram a realização desta pesquisa e do questionário utilizado. Assim, os conhecimentos acerca da temática do RPC e do ensino de Língua Portuguesa nos permitem uma reflexão sobre a importância de trazer à tona a visão atual dos estudantes a respeito das formas avaliativas utilizadas na instituição escolar. 0 foco do RPC é ajudar o educando a se desenvolver plenamente, com auxílio profissional e sem prejulgamentos a partir de um ensino de qualidade, destacando-se que o uso da escala de Likert no meio educacional permitiu compreender as atuais expectativas e necessidades dos estudantes. 
Os resultados obtidos podem ser expostos pelos principais pontos de análise, ou seja, em primeiro lugar está a questão do tempo, tornando-se possível identificar que os alunos não relacionam a grande quantidade de tempo à qualidade de educação, pois a qualidade não se refere ao tempo, mas sim a como o ensino é ofertado. Além disso, sentem-se completamente preparados para ingressar nos exames de qualificação que terão de realizar futuramente.

Desta forma é possível destacar que o ensino em tempo integral nem sempre é visto com bons olhos pelos educandos e mais tempo em sala de aula pode se tornar exaustivo, principalmente se as atividades forem aplicadas de forma tradicional. Por isso, é preciso compreender as demais necessidades dos alunos; é imprescindível um ensino que proponha envolvimento e ludicidade, e usar o diálogo em busca de soluções para um ensino mais didático e em consequência disso mecanismos de avaliação menos tradicionais, pois o ensino integral, segundo a lei, deve ser introduzido nas escolas estaduais, e para que haja aceitação é preciso mudanças, tanto avaliativas como didáticas.

$\mathrm{Na}$ avaliação em sala de aula verificou-se que os professores trabalham com diversos tipos de avaliações, objetivas, subjetivas, e enfatizam a participação do trabalho em grupo, porém as avaliações tradicionais que dão preferência às atividades subjetivas e objetivas ainda são as mais utilizadas. Ante a forma como os alunos julgam ser avaliados e se há a utilização de diferentes formas avaliativas em sala de aula, os resultados mostraram-se positivos principalmente quando as respostas revelam que a presença de julgamento de valor dos professores não interfere nas avaliações. Quanto às formas de avaliação o resultado foi semelhante, os quais indicam estar presentes nas aulas, porém não podem ser deixadas de lado dissonâncias de respostas, que revelam que os alunos não estão atentos à forma como estão sendo avaliados. E essa situação pode infelizmente estar ligada ao ensino tradicional, uma vez que a mentalidade do educando está mais preocupada em seguir diretrizes do que dialogar e construir o conhecimento com seu educador.

A respeito do acompanhamento visamos principalmente à qualidade de ensino. Para os alunos um tempo de aula por dia durante a semana é o suficiente para ter um contato pleno com a Língua Portuguesa. Verificado este ponto, partimos para a questão da utilização de outros profissionais para auxiliar os alunos em sala de aula. Grande parte não mostrou esta necessidade e acredita que apenas o professore titular consegue sanar suas dúvidas em sala de aula, porém embora esta seja a resposta de maior número, podemos identificar que há alunos que não têm da mesma opinião, ou seja, grande parte consegue atendimento, outros não. Além disso, os resultados identificam que nem todos os estudantes têm aula no contraturno quando necessário, o que revela que há necessidade de profissionais qualificados para atender o aluno e para esclarecer as dúvidas, pois o tempo em sala de aula, por vezes, não é suficiente.

A respeito do termo "reprovação" continuamente visto em nossos estudos sobre a temática, os alunos demonstraram que ela ainda existe no meio educacional e considerando que havia alunos que em algum momento tiveram alguma pendência no componente curricular de Língua Portuguesa, é possível identificar que há avaliações no final do ano escolar, às quais os alunos são submetidos, contudo não se sabe ao certo de que forma elas são realizadas. 
Identificamos que embora cada aluno tenha sua individualidade e necessidades, suas percepções a respeito da forma como é avaliado não pode ser vista como absoluta, é preciso diálogo, ouvi-los com mais frequência e expor a importância do ensino. A pesquisa revelou alguns dados que refletem como está o RPC no ambiente escolar, e que a progressão ofertada aos alunos deve andar em compasso com seus direitos. Caso isso não ocorra o resultado será a temida "progressão automática", ou seja, o sistema adentra nas instituições escolares e dá ao aluno a oportunidade de progredir, pois é um direito dele, mas ao invés disso, usado de forma errada retira seu maior direito, a educação.

Esta pesquisa é apenas uma porta aberta para que haja mais reflexões no campo das políticas avaliativas educacionais. O RPC é fundamentado por muitas outras leis e sua aplicação serve de base para pesquisas nos Ensinos Fundamental, Infantil e Médio. Esta é apenas uma pequena percepção da situação atual em que se encontra a educação. A legislação educacional brasileira é ampla, teoricamente é uma das melhores, mas para que isso seja real é preciso pô-la em prática, fazendo-se necessário a propagação de mais pesquisas com o intuito de melhorar o ensino e fazer valer os direitos dos educandos.

\section{REFERÊNCIAS}

AMAZONAS. Conselho Estadual de Educação. Resolução n48, de 2015. Alterações ao Regime Escolar das Escolas Públicas Estaduais. Manaus, 27 mar. 2015.

BACKER, Paul de. Gestão ambiental: a administração verde. Rio de Janeiro: Qualitymark, 1995.

BEZERRA, José Eudes B. Direito a educação e progressão continuada: para além da aparência. São Paulo: Serpente, 2015.

BRANDÃO, Z.; BAETA, A. M. B.; ROCHA, A. D. C. Evasão e repetência no Brasil: a escola em questão. Rio de Janeiro: Achiamé, 1983.

BRASIL. Ministério da Educação. CNE/CEB. Diretrizes Curriculares Nacionais para a Educação Infantil. Brasília, 2013.

BRASIL. Ministério da Educação (MEC). Secretaria de Educação Básica. Ampliação do Ensino Fundamental para nove anos: $3^{\circ}$ Relatório do Programa. Brasília: Ministério da Educação, 2006.

BRASIL. Secretaria de Educação Fundamental. Parâmetros Curriculares Nacionais: terceiro e quarto ciclos do Ensino Fundamental: língua portuguesa. Brasília: MEC; SEF, 1998.

BRASIL. LDB, Lei 9.394/1996. Lei de Diretrizes e Bases da Educação Nacional. Brasília: Senado Federal, 2017.

CAMARGO, D. A. F.de. Fundamentos pedagógicos da progressão continuada. In: MICOTTI, M. C. (org.). Alfabetização: aspectos teóricos e práticos. Rio Claro: Instituto de Biociências, 1999.

CÂNCIO, Raimundo N.; TÁVORA, Maria J.; CÂNCIO, Ana P. A organização da escolaridade em ciclos de aprendizagem: uma análise das experiências na escola Baldoíno Melo-Oriximiná-PA. Pesquiseduca, Santos, v. 8, n. 15, p. 105-120, jan./jun. 2016.

FERREIRA, Sebastião. A progressão continuada nas escolas estaduais e a exclusão silenciosa. São Paulo: Scortecci, 2006.

GUILHERME, Claudia Cristina Fiorio. Práticas docentes do regime de progressão continuada. Araraquara: Junqueira\&Martin, 2007.

HOFFMANN, Jussara M. L. Avaliação: mito e desafio - uma perspectiva construtivista. 30. ed. Porto Alegre: Mediação, 2001.

JEFFREY, Débora Cristina. O regime de progressão continuada: o caso paulista (1998-2004). São Paulo: Unesp, 2011.

LORENZATO, Sergio. Para aprender matemática. 2. ed. Campinas, SP: Autores Associados, 2008.

MARCONI, Marina de Andrade; LAKATOS, Eva Maria. Fundamentos da metodologia científica. 5. ed. São Paulo: Atlas, 2003.

PARO, Vitor Henrique. Reprovação escolar: renúncia à educação. São Paulo: Xamã, 2001. 


\section{\& Contexto}

Daiana dos Santos Reis - Aldair Oliveira de Andrade

PERRENOUD, Philippe. Os ciclos de aprendizagem: um caminho para combater o fracasso escolar. Porto Alegre: Artmed, 2004.

PINSONNEAULT, A.; KRAEMER, K. L. Survey research methodology in management information system: an assessment. Journal of Management Information Systems, v. 10, n. 2, p. 75-105, 1993.

SENA, Odenildo. Palavra, poder e ensino da língua. 2. ed. Manaus: Editora Valer, 2001.

SLOBIN, Dan. Psicolingüística. São Paulo: Edusp, 1980.

SOUZA, Nathanael P.; SILVA, Eurides B. Como entender e aplicar a nova LDB: lei no 9394/96. 1. ed. São Paulo: Pioneira Thomson Learning, 2002.

SOUZA, Sandra. A avaliação na organização em ciclos. In: USP fala sobre educação. São Paulo: USP, 1999. VALENTE, Ivan; ARELARO, Lisete. Progressão continuada X Progressão automática: E a qualidade de ensino? São Paulo: [S. n.], 2002.

VIEIRA, Sonia. Como elaborar questionários. São Paulo: Atlas, 2009. 